\title{
MARIA DO AMPARO TAVARES MALEVAL ( - 2021) E O GT DE ESTUDOS MEDIEVAIS DA ANPOLL: ALGUMAS PALAVRAS
}

\section{Maria do Amparo Tavares Maleval ( - 2021) the Medieval Studies GT of ANPOLL: some words}

\author{
Álvaro Alfredo Bragança Júnior (UFRJ/Brathair) \\ ORCID: https://orcid.org/0000-0003-1768-4077
}

Email: alvabrag@uol.com.br

Recebido em: 10/06/2020

Resumo: Homenagem à Professora Maria do Amparo Maleval e sua relação com a criação do GT de Estudos Medievais da Associação Nacional de Pós-Graduação e Pesquisa em Letras e Linguística (ANPOLL).

Palavras-Chave: homenagem, Maria do Amparo Maleval, criação, GT de Estudos Medievais da ANPOLL.

Abstract: Testimony in homage to Professor Maria do Amparo Maleval and her role for the criation of the Medieval Studies GT of ANPOLL.

Keywords: Homage, Maria do Amparo Maleval, Medieval Studies GT of ANPOLL. 
Para a produção intelectual de Maria do Amparo Tavares Maleval vide http://buscatextual.cnpq.br/buscatextual/visualizacv.do?id=K4787495D5

Em 1999, durante o III Encontro de Estudos Medievais da Associação Brasileira de Estudos Medievais, realizado na UERJ e coordenado pela professora Maria do Amparo, ainda como recém-doutor, tive o privilégio de conhecê-la. Em seis anos de conhecimento acadêmico percebi o quanto a professora Maria do Amparo era uma séria e dedicada pesquisadora. Em 2005, na UERJ, foi feita a sugestão de criação de um GT de Estudos Medievais da Anpoll - Associação Nacional de Pós-Graduação e Pesquisa em Letras e Linguística -, tendo sido a sugestão aprovada por unanimidade na Assembleia realizada no dia 22 de junho de 2005, durante o XX Encontro da Anpoll, transcorrido de 20 a 22 de junho de 2005, na Pontifícia Universidade Católica/PUC de São Paulo.

Gostaria de destacar, nesse momento, um fato importante: como participante de eventos relacionados à Idade Média e integrante, naquele momento, como membro efetivo do Programa de Pós-Graduação em História Comparada, naquela época inserido dentro do Instituto de Filosofia e Ciências Humanas da Universidade Federal do Rio de Janeiro, mas docente efetivo e lotado na Faculdade de Letras da mesma Universidade, fui o Vice-Coordenador do GT, como convidado, sendo minha participação aceita e referendada por todos os membros fundadores do Grupo de Trabalho. Não tenho dúvidas de que a professora Maria do Amparo Tavares Maleval contribuiu e muito para que pudesse integrar este GT desde sua gênese.

O GT de Estudos Medievais teve como membros fundadores os seguintes Professores Doutores:

\section{Maria do Amparo Tavares Maleval (UERJ) (Coordenadora do GT)}

Álvaro Alfredo Bragança Júnior (UFRJ) (Vice-Coordenador do GT)

Ângela Vaz Leão (PUC-Minas)

Célia Marques Telles (UFBA) 


\section{Delia Cambeiro Praça (UERJ)}

Elizabeth Dias Martins (UFC)

Francisco Roberto S. de Pontes Medeiros (UFC)

Gladis Massini-Cagliari (UNESP)

Lênia Márcia Mongelli (USP)

Márcio Ricardo Coelho Muniz (UEFS)

Maria Helena Sansão Fontes (UERJ)

Paulo Roberto Sodré (UFES)

Regina Michelli (UERJ)

Risonete Batista de Souza (UFBA)

Vanda de Oliveira Bittencourt (PUC-Minas)

Viviane Cunha (UFMG)

Yara Frateschi Vieira (UNICAMP)

Do mesmo modo, durante poucos meses, fiz parte da Direção da ABREM como Primeiro Tesoureiro, porém por razões pessoais de ordem familiar, fui obrigado a me desligar dessa função. Lá estava também na Diretoria a professora Maria do Amparo!

E assim foi o contato nos eventos da área de Medieval pelo Brasil, nos encontros da ABREM. Ficou em 2021 a lacuna da presença física, mas os livros, os eventos organizados, a participação efetiva em diretorias científicas e, principalmente, o lado humano da docente, pesquisadora, autora e colega não estarão ausentes. Mudando o conhecido provérbio latino, Figura volat, solitas manet! 